\title{
ENHANCING THE DESTINATION IMAGE THROUGH PROMOTING POPULAR RIVER CRUISE DESTINATIONS \\ Maksym Dimitrov $^{1}$, Mariya Zlatkova Stankova ${ }^{2}$
}

\begin{abstract}
The sector of cruise tourism is growing in both subdivisions: river and ocean cruises. The most popular river cruise destinations in Europe are connected with historical places around big rivers such as the Danube, Rhine, Volga and others. One cruise itinerary consists of several tourist destinations, well-known and unknown for the cruise tourist, and creates one tourist destination combined with different ports of call. The well-known ports of call such as Paris, Vienna, St. Petersburg are the main attraction for the tourists.

Among them there are some ports of calls which the tourist is not familiar with before visiting them. River cruise tourists have the opportunity to discover smaller cities in the chosen country or visit a new country as a tourist destination. For the areas where tourism is in a very early developing stage it is crucial to create a unique destination image which could influence the future choice of the tourists and bring them back.

The study focuses on the main objective of exploring the attitudes of tourists traveling on two European river cruise routes, their experience and satisfaction within the visited destinations. The research has a scientifically applied character, outlining certain attitudes that would be of interest to the business operating on river cruise destinations. Research results show that popular cities are a pull factor for river cruise tourism. Integrating them into the tourism offer as part of the long-term tourism planning would bring benefits to the destination by contributing to the creation of a unique and attractive destination image and growing popularity.
\end{abstract}

JEL Classification Numbers: L83, Z31, Z32, Z38, DOI: 10.12955/cbup.v7.1340

Keywords: river cruises, tourist destinations, destination image.

\section{Introduction}

Cruise tourism is very specific type of tourism, which is facing phenomenal fast development in the tourism industry (Dowling, 2006). Undoubtedly, this is also evident from the expectations of the World Tourism Organization which back in 2011 estimates that by 2030 international tourist arrivals will reach 1.8 billion tourists per year. Over the last 50 years, cruise tourism has been a relatively young phenomenon. During this period the average annual growth rate was approximately $8 \%$, which exceeds that of tourism in general. River cruise tourism in Europe is booming as it offers to its guests a large variety of attractions: historical landmarks, art and culture, natural resources and gastronomy. According to the Annual report (2018) of Inland Navigation in Europe Market Observation, the river cruise fleet in Europe comprised 346 active vessels with 50,616 beds. The number of active cruise vessels more than doubled between 2004 and 2017. In 2017, 17 vessels were introduced to the market with 2,558 beds. This newbuilding volume represented $5 \%$ of the existing fleet. As seven ships were removed from the fleet in 2017, the net increase in 2017 was 11 vessels with approximately 1,770 beds, representing $3.6 \%$ of the existing fleet.

River cruise tourism attracts tourists with main cities on the itinerary and at the same time it offers to explore smaller ports. It has a direct influence on tourism development in the regions. Our study is examining two cities on two different river cruise itineraries in Europe. The first city is Bratislava (Slovakia) which is included in the Danube Waltz cruise (DW) with the main attractive cities being Vienna and Budapest. The second city we examine in our study is Yaroslavl (Russia) which is a part of the River of Tsars cruise (RT) on the Volga River and Russian waterways with its main attractive cities being St. Petersburg and Moscow. Both cities have rich touristic potential and similar characteristics in terms of historical background, architectural diversity and cultural heritage.

With our current study we aim to analyze visitors' perception of the destination image of these two cities and to define how the choice of river cruise stops influenced the other destinations which are not well known. In a broader sense, the study allows us to find out how river cruise tourism could impact upon regional tourism development.

\section{Literature review}

River cruise tourism has many specifics and one of them is gathering a few separate tourist destinations into one itinerary and by doing this, a new tourist destination can be established. Davidoff and Davidoff (1993) describe cruise tourism as an opportunity to visit a variety of places in a short period of time

\footnotetext{
${ }^{1}$ South-West University “Neofit Rilski”, Blagoevgrad, Bulgaria, m.n.dimitrov@ gmail.com

${ }^{2}$ South-West University “Neofit Rilski”, Blagoevgrad, Bulgaria, mzlstan@ yahoo.com
} 
without the problems of other modes of travel. River cruise tourism combines several tourist destinations on one itinerary and allows the tourist to visit all of them in a short period of time with very organized logistics and comfortable stays. Each visited port of calls is a part of the river cruise destination and has its impact for the general perceived quality and customer satisfaction from the cruise. In addition to that, together with well-known and attractive tourist destinations, tourists discover new countries and cities. Moreover, such characteristics make river cruise tourism an excellent opportunity for stimulating economic and socio-cultural impact.

Presumably, the cruise industry introduces as destination cruise itineraries which are already pre-set, and the guest doesn't have a choice to decide which city to visit within the itinerary (Ahmed, Johnson, Ling, Fang \& Hui 2002). Thus, a guest chooses the itinerary as a tourist destination. With this choice of particular importance is the image of the destination, which definitely affects tourists' personal perceptions and choice motivation. Of course, the conceptual framework of the tourist destination image is widely studied within the tourism literature. In the world of competitiveness in the tourist market, the destination positioning strategy has an important role for promoting a tourist destination (Hunt, 1975; Echtner and Ritchie, 1991).

The images held of such attributes as the natural environment, climate, and people of a destination are likely to detract from, or contribute to, successful tourism development (Fakeye and Crompton, 1985). The destination image is defined as an expression of all objective knowledge, impressions, prejudice, imaginations, and emotional thoughts an individual or group might have of a particular place, connected with people, climate and attractions (Hunt et al., 1975; Lawson and Baud Bovy, 1977). According to Gartner (1993) there are three main dimensions of destination image - cognitive, affective and conative. According to Echtner and Ritchie (1993) the destination image is a multidimensional concept comprising of both symbolic and tangible features and it has the following dimensions:

- destination image should be envisioned as consisting of two main components: those that are attribute based and those that are holistic;

- each of these components contains functional, or more tangible, and psychological, or more abstract, characteristics;

- the image of the destinations can also range from those based on "common" functional and psychological traits to those based on more distinctive or even unique features, events, feelings or auras.

The destination image is influenced by the quality of experience, attractions, value/environment, relaxation/escape, excitement/adventure, knowledge, social and prestige (Baloglu and McCleary, 1999). In effect, it is a mental representation of knowledge, feelings and overall perception of a particular location. Beerli and Martin (2004) state that the destination image consists of views about natural and cultural resources, general, tourist and leisure infrastructures, atmosphere, social setting and environment, sun and sand, knowledge, relaxation, entertainment, and prestige.

A cruise ship combines elements across all sectors of tourism (Brida \& Zapata, 2010). Touristic attractiveness of the cruise ports is determined by four factors (Aslanoglu \& Balakan 2016):

- climate, culture and natural factors of the destination;

- docking location of the ship and distance to the main tourist attractions;

- the appropriate transportation features such as port infrastructure;

- cruise ship services and passenger services.

Cruise companies include destinations in their itineraries mainly based on the attractiveness of ports of call (Razović, 2018). This includes a possibility of additional income for the cruise liner company from trips and organized visits for the cruise tourist in a destination and based on the complete characteristics of the supply in the related ports.

Touristic attractiveness is directly influencing the competitiveness of the tourist destination. According to Kozak (1999), the competitiveness is the key element of the management and marketing strategy, therefore long-range planning and customer satisfaction should be the two major objectives of either the tourism businesses or tourist destinations. Hassan (2000) refers competitiveness to a destination's ability to create and integrate value-added products that sustain its resources while maintaining market position relative to competitors. Govers and Go (2007) consider tourism completeness like success in integrated quality management. In connection to that, when researching the destination competitiveness, they 
suggest seven attributes, including attractiveness. Definitely, the approaches to competitiveness currently are noticeably interdisciplinary, but also, most of them are inherently measuring competitiveness using information about the perceptions of tourists and their opinions of experiences in different countries (Stankova, 2014).

\section{Methodology}

The data for this study was collected from a survey questionnaire which was provided to the tourists on both river cruise itineraries. In our study as a tourist destination we observed Bratislava and Yaroslavl, which are part of the DW and RT accordingly. The DW cruise included following ports of calls on the Danube River: Passau (Germany), Linz, Durnstein, Vienna (Austria), Bratislava (Slovakia), and Budapest (Hungary). The duration of the cruise is 8 days. The amount of time for visiting the Bratislava port is limited to 6 hours. The main attractive cities on the DW itinerary are Vienna and Budapest. The second city we examine in our study is Yaroslavl (Russia) which is a part of the River of Tsars cruise (RT) on the Volga River and Russian waterways. Its duration is 13 days and included the following ports in Russia: Saint Petersburg, Mandrogy, Kizhi Island, Kirilov, Yaroslval, Uglich and Moscow. The time spent in Yaroslavl is up to 6 hours. The main reason to take this cruise is two cities: St. Petersburg and Moscow. Both cities have rich touristic potential and similar characteristics in terms of historical background, architectural diversity and cultural heritage.

The questionnaire form was developed by authors. It consists of two sections. The first section of the questionnaire elicited general and biographical information about the respondents. The second section requested participants to answer 22 questions related to the destination evaluation including I. destination environment, II. destination attractiveness, III. destination comfort. Attitudes to each of the item scales used in the questionnaire were assessed using a five-point Likert scale based on " $1=$ strongly disagree" to " $5=$ strongly agree".

In order to analyze the collected data, quantitative research methods were used in the present study. A preliminary questionnaire was tested on a small group of river cruise travelers. The reliability of the scale was tested, and the Cronbach's alfa value was significantly high with the result on the DW cruise of $0.96,0.91$ and 0.95 respectively for each factor. According to Nunnaly (1978), the $\alpha$ is considered reliable when the indicator is above 0.7 . This result enabled approving the survey and the questionnaire form was given to 386 river cruise passengers in total (190 guests on the DW ship and 196 guests on the RT ship). The data were collected between the dates of 26 of July 2018 and 29 of August 2018. In total 301 questionnaires were returned back.

The study uses a factor analysis approach in order to identify factor loadings of the tourist destination attributes for Bratislava and Yaroslavl and their impact on the destination image formation from the river cruise passengers' prospective.

As a tool of modern multidimensional statistics, factor analysis is widely applied in various fields of research (Lawley \& Maxwell, 1962). According to Stankova \& Vasenska (2015), it is also relevant to tourism and tourist destination, considered their complex systems. In this case, factor analysis allowed for these key task to be solved:

- to determine the amount of the relevant factors and their impact on the destination image;

- to establish the factor structure of the studied attributes or to show the level of their impact on the preliminary destination image formation of the river cruise passengers.

\section{Results and discussion}

The questionnaires were delivered to each guest. The total amount of the returned questionnaires on the "Danube Waltz" (DW) itinerary was 143, and for the "River of Tsars" (RT) itinerary it was 158. As it shown in Table 1, female passengers are in the majority of participants in the survey on both ships DW: $57.86 \%$ females and $42.14 \%$ males; RT: $62.34 \%$ females and $37.66 \%$ males. Similar age ranging could be noticed for each ship.

For DW only $1.4 \%$ were between the ages $40-54$, the majority of passengers were over the age of 55 : $44.4 \%$ between $55-69,35.9 \%$ between $70-84$, and $18.3 \%$ over 85 . RT has equal number of passengers in the range of under 39 and $40-54-1.3 \%$ each. The majority of the passengers are over 55 years old with $51.6 \%$ for the range of $55-69,31.6 \%$ for $70-84$, and $14.2 \%$ for over 85 . These numbers confirm the statement of Dowling (2006) that traditionally cruising has been the preserve of older people, mainly 
retirees. The Baby boomers are the major part of cruise passengers, but some changes in demographic changes are on the way and according to Dowling (2006), the average age of cruise passengers is decreasing, and it is no longer seen as the preserve of senior retirees.

Table 1: Profile of participants

\begin{tabular}{|c|c|c|c|c|c|}
\hline & & \multicolumn{2}{|c|}{ Passau - Budapest } & \multicolumn{2}{|c|}{ Moscow - St. Petersburg } \\
\hline & & $\mathbf{N}$ & $\%$ & $\mathbf{N}$ & $\%$ \\
\hline \multirow[t]{3}{*}{ Gender } & Male & 59 & 42.1 & 58 & 37.7 \\
\hline & Female & 81 & 57.9 & 96 & 62.3 \\
\hline & Total & 140 & 100.0 & 154 & 100.0 \\
\hline \multirow[t]{6}{*}{ Age } & Under 39 & 0 & 0.0 & 2 & 1.3 \\
\hline & $40-54$ & 2 & 1.4 & 2 & 1.3 \\
\hline & $55-69$ & 63 & 44.4 & 80 & 51.6 \\
\hline & $70-84$ & 51 & 35.9 & 49 & 31.6 \\
\hline & $85-99$ & 26 & 18.3 & 22 & 14.2 \\
\hline & Total & 142 & 100.0 & 155 & 100.0 \\
\hline \multirow[t]{5}{*}{ Education } & Elementary school & 13 & 9.5 & 10 & 6.5 \\
\hline & High school & 23 & 16.8 & 28 & 18.1 \\
\hline & College degree & 66 & 48.2 & 65 & 41.9 \\
\hline & University degree & 35 & 25.5 & 52 & 33.5 \\
\hline & Total & 137 & 100.0 & 155 & 100.0 \\
\hline \multirow[t]{6}{*}{ Nationality } & Australia & 2 & 1.4 & 8 & 5.1 \\
\hline & Canada & 30 & 21.1 & 26 & 16.5 \\
\hline & U.K. & 14 & 9.9 & 52 & 32.9 \\
\hline & U.S.A. & 96 & 67.6 & 68 & 43.0 \\
\hline & Other countries & 0 & 0.0 & 4 & 2.5 \\
\hline & Total & 142 & 100.0 & 158 & 100.0 \\
\hline \multirow[t]{3}{*}{ Occupation } & Working & 44 & 30.8 & 39 & 24.8 \\
\hline & Retired & 99 & 69.2 & 118 & 75.2 \\
\hline & Total & 143 & 100.0 & 157 & 100.0 \\
\hline \multicolumn{2}{|c|}{ Total participants } & 143 & & 158 & \\
\hline \multicolumn{2}{|c|}{ Total occupancy } & 190 & & 196 & \\
\hline
\end{tabular}

By nationality most of the guests were from USA with $67.6 \%$ for DW and $43 \%$ for the RT cruise followed by UK guests with $9.9 \%$ and $32.9 \%$, Canadians with $21.1 \%$ and $16.5 \%$, Australians with $1.4 \%$ and $5.1 \%$ for both cruises accordingly. The RT cruise had as well $2.5 \%$ other nationalities.

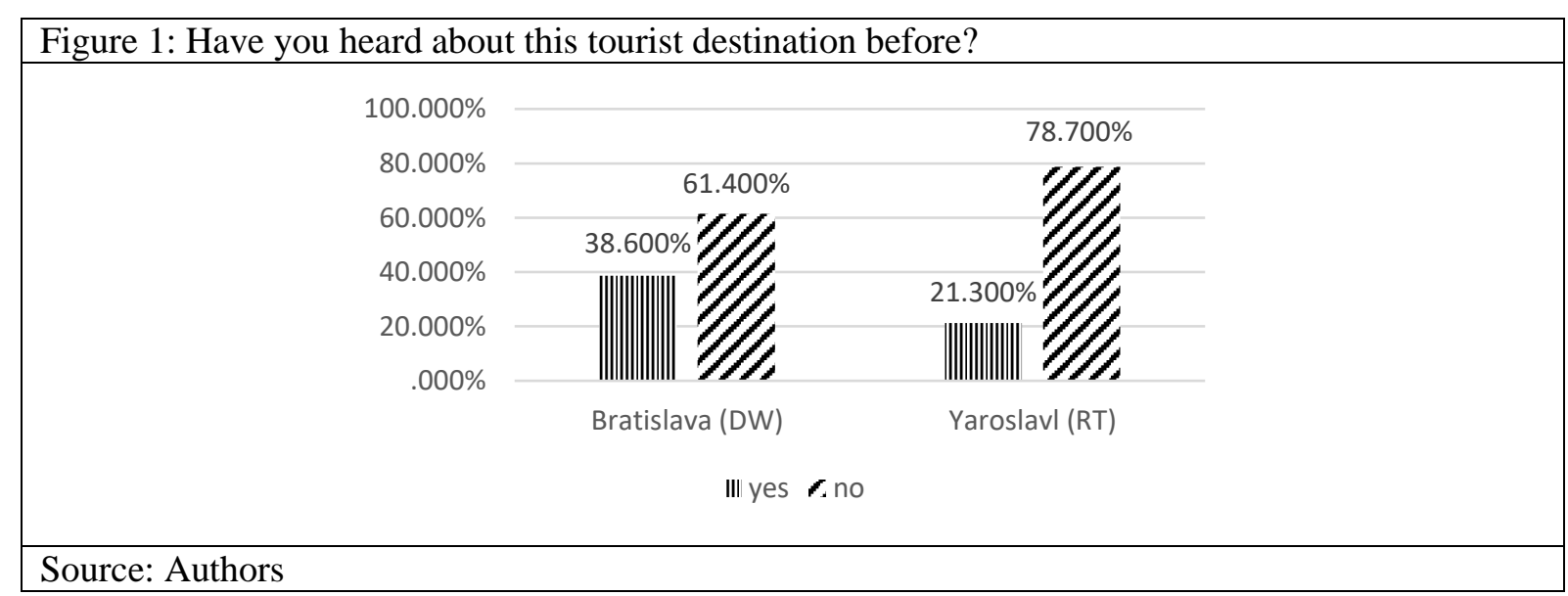

Figure 1 shows that most of the passengers haven't heard about this tourist destination before. Bratislava (DW) was known as tourist destination before the visit for only $38.6 \%$ of passengers of the ship. For Yaroslavl (RT) this indicator was only $21.3 \%$. The cruise itineraries are pre-set, and the guest has no choice in deciding which city to visit within the cruise. Most of the respondents did not have any preliminary expectations for these cities and as they mentioned in the survey the main attractive cities were Vienna and Budapest for the DW cruise, or St. Petersburg and Moscow for the RT cruise. 
In this study an assertive methodology, the factor analysis, enables the identification of the factor load for each of the defined factors as the relevant preliminary destination image formation of the river cruise passengers as it shown in Table 2.

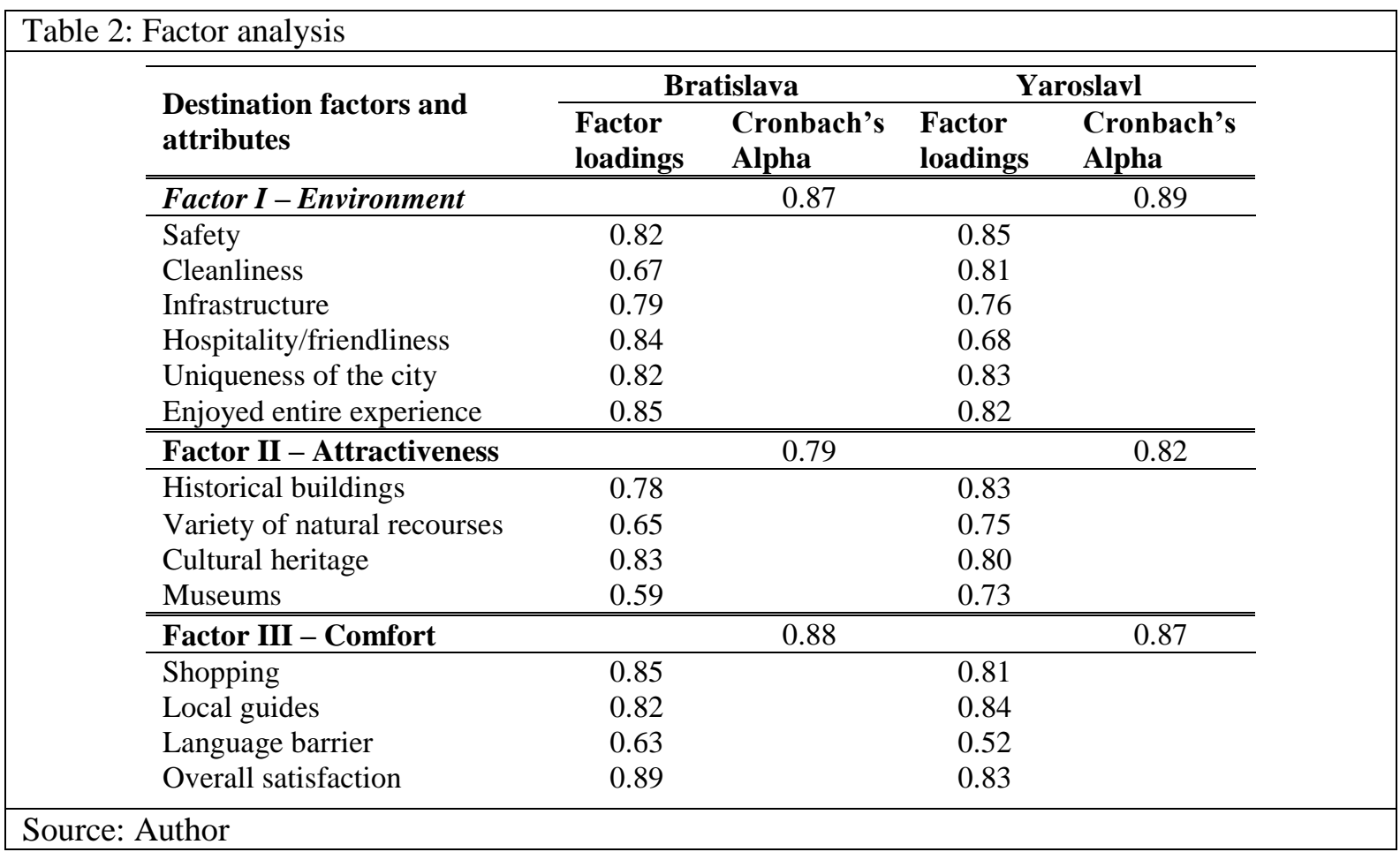

The reliability of the scales was analyzed by means of the Cronbach's alpha coefficient for each factor. The first factor was defined as "destination environment". It shows the attributes about safety, cleanliness, infrastructure, hospitality, uniqueness of the city, and general experience in both towns. The factor loading scores for these attributes ranged from 0.67 to 0.85 for Bratislava and from 0.68 to 0.85 for Yaroslavl. The second factor was defined as "destination attractiveness". It consists of the following attributes: historical buildings, variety of natural recourses, cultural heritage and museums. The factor loading scores for these attributes ranged from 0.59 to 0.83 for Bratislava and from 0.73 and 0.83 for Yaroslavl. The third factor was defined as "destination comfort". It combined the following attributes: shopping, local guides, language barrier and overall satisfaction. The factor loading scores for these attributes ranged from 0.63 to 0.89 for Bratislava and from 0.52 to 0.84 for Yaroslavl. The Cronbach's $\alpha$ values for both cities ranged from 0.79 to 0.89

The tourist potential is connected with rich historical and cultural background. Both cities are unique with their architectural monuments and buildings. The passengers experienced language barriers when communicating with locals.

Guests were asked to describe what would be the main reason to visit these two cities. The question was offered with following options "culture", "architecture", "natural recourses", "gourmet", "sport activities", "relaxation" from which they choose few and/or add their own reason. Results show that most of the passengers connect Bratislava with "culture" (125 answers), "relaxation" (113 answers), "architecture" (82 answers), "natural resources" (39 answers), "gourmet" (27 answers), "sport activities" (22 answers), "visiting relatives" ( 2 answers). The main reason for Yaroslavl is "culture" as well (130 answers), "architecture" (125 answers), "relaxation" (103 answers), "gourmet" (115 answers) "natural resources" (73 answers), "sport activities" (27 answers), "exploring soviet past" (3 answers), "visiting friends" (2 answers).

Even the destination image analysis is positive and scores are very high for each component, the answer on the question "If the main attractive city was not part of the cruise would you have done the cruise anyway?" most of the tourist answered negatively (Table 3 ). 
Table 3: If the main attractive city was not part of the cruise would you have done the cruise anyway?

\begin{tabular}{|l|c|c|c|c|}
\hline & \multicolumn{2}{|c|}{ Bratislava } & \multicolumn{2}{c|}{ Yaroslavl } \\
\hline Yes & 34 & $23.8 \%$ & 35 & $22.2 \%$ \\
\hline No & 89 & $62.2 \%$ & 103 & $65.2 \%$ \\
\hline Maybe & 20 & $14.0 \%$ & 19 & $12.0 \%$ \\
\hline Total & 143 & & 158 & \\
\hline
\end{tabular}

Source: Author

For both cities the results are similar, as $62.2 \%$ and $65.2 \%$ of passengers answered "no" respectively for Bratislava and Yaroslavl. Only $23.8 \%$ and $22.2 \%$ of the respondents answered "yes". There is a small group of passengers who are not sure, and the answer "maybe" was given by $14 \%$ and $12 \%$ of passengers.

\section{Conclusion}

The survey of the attitudes of tourists traveling on two European river cruise routes, their experience and satisfaction within the visited destinations was primarily oriented towards the analysis of their perception of the destination image as well as towards defining how the choice of river cruise stops is influenced if the other destinations are not well known. Two cities are the focus of attention - Bratislava and Yaroslavl. Being included in the itinerary as ports of call, it means that there is necessary infrastructure for nautical vessels. Bratislava and Yaroslavl have very good river ports and both cities are able to facilitate river cruise tourists. By projecting the effect on unfamiliar tourist destinations on the cruise itinerary in practice it was shown that they affect the choice of cruise passengers. In fact, however, in a broader sense, the study revealed the wider impact river cruise tourism could have on regional tourism development.

In order to investigate passengers' perception of the visited cities, destination image factors were used. The results showed that the majority of tourists were satisfied with their visit. The historical and cultural heritage and the diversity of architecture styles of the buildings created a unique destination image. The environment is safe, and the cities are clean. Local people are friendly, and food is great. The gained knowledge and experiences are evaluated as "very good" and "excellent" as well. Overall here was a very positive destination image. This is why the passengers answered that they "would speak highly of this tourist destination to friends and colleagues". At the same time Bratislava and Yaroslavl are not determined as the reason to choose the cruise.

The summary of the results and the conclusions highlighted that popular cities are the pull factor for river cruise tourism. It could be stated that for any port of call its inclusion in the river cruise itinerary is a great advantage for the regional cruise development. River cruise tourism could be determinant indicator for tourism development and improvement in order to create a unique and attractive destination image which makes the tourist destination more popular.

\section{References}

Ahmed ZU, Johnson JP, Ling CP, Fang TW, Hui A. K. (2002). Country of origin and brand effects on consumers' evaluations of cruise lines. Int. Mark. Rev., 19(3): 279-302

Aslanoğlu, E., Balakan, A. (2016). An analysis of cruise tourism on Turkish economy; a case study for Istanbul and Barcelona ports. Yildiz Social Science Review, 2 (2), 1-28.

Baloglu, S. \& McCleary, K.W. (1999). A model of destination image formation, Annals of Tourism Research, Vol. 26, No. 4, pp. 868-897. https://doi.org/10.1016/S0160-7383(99)00030-4

Beerli, A., and Martin, J. D. (2003). Tourists' characteristics and the perceived image of tourist destinations: a quantitative analysis - a case study of Lanzarote, Spain. Tourism Management, (25), 623-636.

https://dx.doi.org/10.1016/j.tourman.2003.06.004

Brida, J.G. and Zapata, S. (2010) Cruise tourism: economic, socio-cultural and environmental impacts, Int. J. Leisure and Tourism Marketing, Vol. 1, No. 3, pp.205-226

Davidoff, P.G. and Davidoff D.S. (1994). Sales and Marketing for Travel \& Tourism, 2nd ed, Prentice Hall, UK

Dowling, R. (2006). Cruise Ship Tourism. Wallingford: CABI p. 3

CCNR Market Observation, (2018). Annual report 2018, https://inland-navigation-market.org/wp-

content/uploads/2019/08/ccnr_2018_Q2_EN_CCNR_annual_report_EN_2018_BD_3-min.pdf 
Govers, R.M. and Go, Fr. (2007). Promoting Tourism Destination Image. Journal of Travel Research - J TRAVEL RES. 46. $15-23$.

Echtner, C.M., \& Brent Ritchie, J.R. (1991). The Meaning and Measurement of Destination Image. The Journal of Tourism Studies, 2, 2-12 University of Calgary. Unpublished paper

Echtner, C.M. \& Ritchie, J.R.B. (1993). The Measurement of Destination Image: An Empirical Assessment. Journal of Travel Research, 31 (4), 3-13.

Hassan, S. S. (2000). Determinants of Market Competitiveness in an Environmentally Sustainable Tourism Industry. Journal of Travel Research, 38(3), 239-245. https://doi.org/10.1177/004728750003800305

Hunt, J. D. (1975). Image as a Factor in Tourism Development. Journal of Travel Research, 13 (Winter): 1-7

Fakeye, P.C. \& Crompton, J.L., (1985). Image Differences between Prospective, First-Time, and Repeat Visitors to the Lower Rio Grande Valley. Journal of Travel Research, 30: 10, https://doi.org/10.1177/004728759103000202

Gartner, W. (1993). Image Formation Process. In M. Uysal, \& D. Fesenmaier (eds.), Communication and Channel Systems in Tourism Marketing (pp.191-215). New York: The Harworth Press. https://doi.org/10.1300/J073v02n02_12

Kim, J. (2014), The antecedents of memorable tourism experience: The development of a scale to measure destination attributes associated with memorable experiences, Tourism Management, Vol. 44, pp. 34-45.

https://doi.org/10.1016/j.tourman.2014.02.007

Kozak, M. (1999). Destination Competitiveness Measurement: Analysis of Effective Factors and Indicators. European Regional Science Association Conference Papers, Dublin.

Lawley, D. N. \& Maxwell, A. E. (1962) Factor Analysis as a Statistical Method. Journal of the Royal Statistical Society. Series D (The Statistician) Vol. 12, No. 3, pp. 209-229, https://dx.doi.org/10.2307/2986915

Lawson, F., and Baud-Bovy, M. (1977), Tourism and Recreational Development. London: Architectural Press.

Nunnally, J. C. (1978). Psychometric theory (2nd ed.). New York, NY: McGraw-Hill.

Rajesh, R. (2013). Impact of Tourist Perceptions, Destination Image and Tourist Satisfaction on Destination Loyalty: A Conceptual Model. PASOS. Revista de Turismo y Patrimonio Cultural, 11 (3), 67-78.

Rasovic, M. (2018). The Role of Cruising Tourism in Tourism Development of Split, Economic Problems of Tourism Vol. 4 (36), pp. 197-209. https://dx.doi.org/10.18276/ept.2016.4.36-18

Stankova, M., \& Vasenska, I. (2015). Competitiveness and Tourism Development-In Search of Positive Image-

Representations of Bulgaria as a Destination. Ekonomika, 61(3), 43

World Tourism Organization (2010a), Cruise Tourism - Current Situation and Trends, UNWTO, Madrid, pp. xviii.

World Tourism Organization (2011), Tourism Towards 2030 - Global Overview, UNWTO, Madrid, pp. 15 